\title{
WATER RESOURSES IN GREECE : PRESENT AND FUTURE
}

\author{
M.A. MIMIKOU*
}

\author{
National Technical University of Athens \\ Faculty of Civil Engineering \\ Department of Water Resources \\ Hydraulic and Maritime Engineering \\ Iroon Polytechniou 5, 15780 Athens, Greece
}

*to whom all correspondence should be addressed

e-mail: mmimikou@chi.civil.ntua.gr
Received: 24/05/04

Accepted: 30/08/04

\begin{abstract}
The European Water Framework Directive 2000/60 has established a new legislation for sustainable management of water resources and protection of their relevant eco-systems. The primary objective of the Directive which is the achievement of acceptable water quality through the implementation of rational water resources management plans presupposes the planning and implementation of a national water policy.

The hydrologic regime in Greece corresponds to other Mediterranean countries of the European Union due to the inadequate availability of water resources and the Mediterranean hydroclimatic conditions. Water demands in several areas of Greece are not satisfactorily covered, while these regions experience an "endemic" shortage of water that appears to be critical. This situation needs an immediate confrontation. The "best institutional and policy practice" for water management appears to be urgently required, along with the creation of a lasting network of institutional research policy for enhancing the productivity of water, at national and local levels.
\end{abstract}

KEYWORDS: water use, water resources, water management, national policy

\section{INTRODUCTION}

Water, along with air and land, are the main sources that contribute to human's life. Water is not only a basic element for life and environment in our planet, but also a regulating factor for economic, technological, social and cultural development. Furthermore, it is an international issue that creates geopolitical conflicts -it is assumed to be the cause of a future war- among neighbouring countries, who share waters from transboundary rivers, lakes and underground aquifers. Even if the water appears to exist in abundance, as the $70 \%$ of earth surface is covered by water, the finally available quantity with suitable quality for use is very small. The $98 \%$ of water is found in the sea, the ocean and the ice, while the rest is not practically exploitable (eg it is found in depth exceeding the $800 \mathrm{~m}$ ) or it is brackish and cannot be used. Only $0.6 \%$ of water worldwide is considered available and suitable for use. This limited quantity of water resources is unevenly distributed in space and time. There are countries with abundance of water and others with vital shortages or deserts. Even in the interior of countries, the water resources are not uniformly distributed, subsequently causing serious local conflicts among the users. The time availability is also uneven, as the winter water is often flash flood, while in summertime it is insufficient for certain use (irrigation, tourism etc). The exceptionally limited availability of water, along with the uneven space-time distribution and the gradually degrading quality, render the water resources inadequate. 
In order to properly utilize the water resources and face all the negatives facts, urgent activities should be taken [1]. Hydraulic works ensure the sufficiency of water depending on demand, regulate the flow distribution in time (eg reservoirs), distribute water in space (eg networks of water supply), protect from the flood action (flood-preventing works) and maintain the water quality (eg biological installations). These works improve the water availability for various uses (rural, urban, industrial, energy). Water resources, hydraulic works and water uses are interrelated and inter-influenced factors, composing the whole water sector of a country. Therefore, a national policy is required for management and decisions.

The right estimation and forecasting of water resources, the suitable planning of hydraulic works and the rational water management on a country or regional level (hydrological basin or region) are essential prerequisites for planning and implementing a national water policy. The Water Framework Directive 2000/60, which is under development in a European level, supports significantly the establishment of national and European water policies and strategies. The Directive primarily aims at maintaining a "good ecological status" of water aquifers through the study and application of "management plans" for each hydrological region. The Directive handles the water sector as an entity, while it retains high requirements and specifications for a series of components of the water cycle, such as surface waters, underground and marine waters, ecosystems etc. All the European countries -and naturally Greece- are compelled to conform to this "constitutive map" of waters, in the next years.

Greece -in view of its commitment for the implementation of the Directive- is found unready and unorganized in the sector of water. A lot of things have to be settled, some of which will be analyzed in this article.

\section{WATER RESOURCES AND WATER USE IN GREECE}

\subsection{Existing water resources}

Water resources refer to the water "produced" inside a country in conjunction with the external water contribution from the neighbouring countries (eg transboundary rivers). Precipitation and evaportranspiration, in combination with the natural characteristics of underground aquifers, establish the main climatic variables that determine the quantity of internally produced water resources. Precipitation constitutes the main component of the surface and underground water enrichment. The mean precipitation of the Mediterranean European countries is $840 \mathrm{~mm} /$ year, while in Greece it approaches the $850 \mathrm{~mm} / \mathrm{year}$. Figure 1 demonstrates the distribution of the mean annual precipitation for the Mediterranean European countries (EUROSTAT data) [2], presenting also inland fluctuations for each one, while Figure 2 demonstrates this distribution for Greece.

It is apparent from Figure 2 that a peculiar hydrologic pattern takes place in Greece: Western Greece accepts the majority of rainfalls, more than $1500 \mathrm{~mm} /$ year, while Eastern Greece, along with the islands of Aegean and Crete, have considerably smaller rainfalls e.g Attica's mean interannual precipitation is approximately $400 \mathrm{~mm} / \mathrm{year}$. On the other hand, the evaportranspiration is an important hydrological loss that takes place both from the surface and the upper territorial layers. The value of evaportranspiration is quite high, especially in the dry Eastern regions of the country. Its maximum is called potential evaportranspiration. A widely used indicator for the climatic characterization of a region is the UNESCO' $s$ indicator of dryness, defined as the ratio of the mean annual precipitation to the corresponding potential evaportranspiration.

Values below 0.20 characterize dry regions, between 0.20 and 0.49 almost dry, between 0.50 and 0.74 almost humid, while values over 0.75 characterize humid regions. Figure 3 presents the map of the UNESCO' $s$ indicator of dryness for the Mediterranean countries [2]. Figure 4 shows the distribution of the same indicator in Greece, indicating the previously mentioned hydrological particularity, along with the severity of drought that affects South-eastern Greece and the islands of Aegean. 


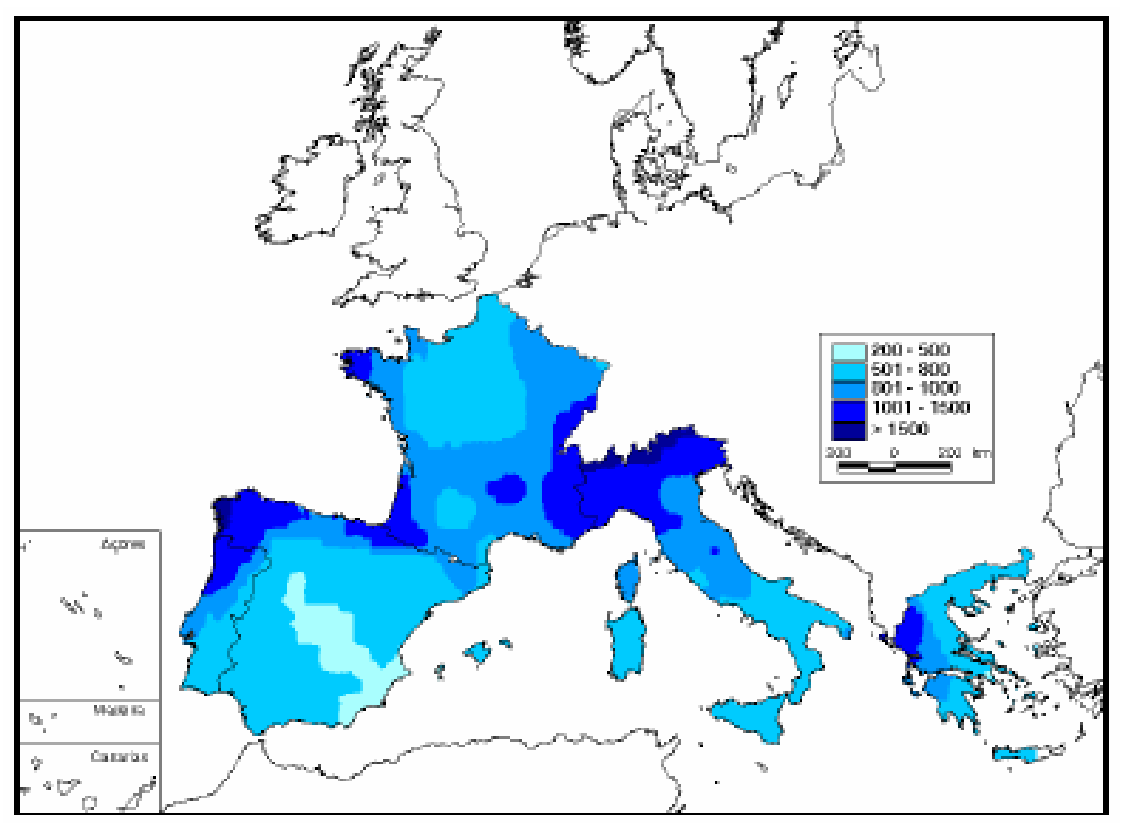

Figure 1. Average annual precipitation (mm) for the period $1960-1990$ in the European Mediterranean Countries

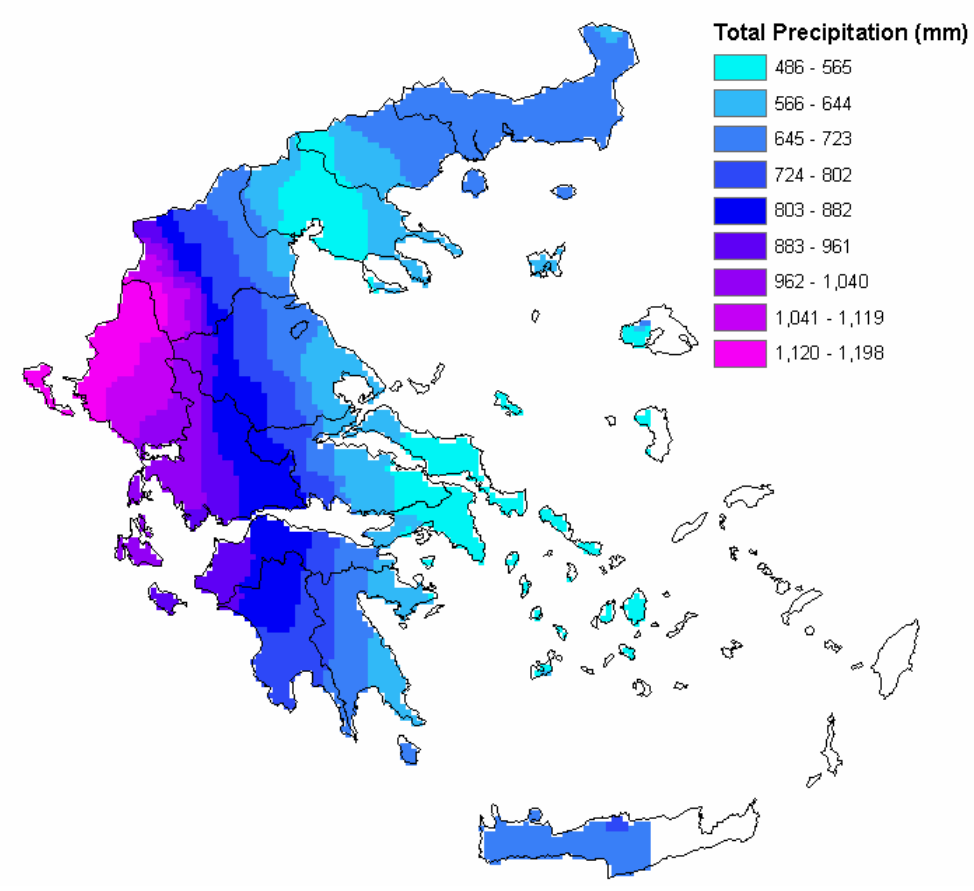

Figure 2. Distribution of total precipitation in Greece 


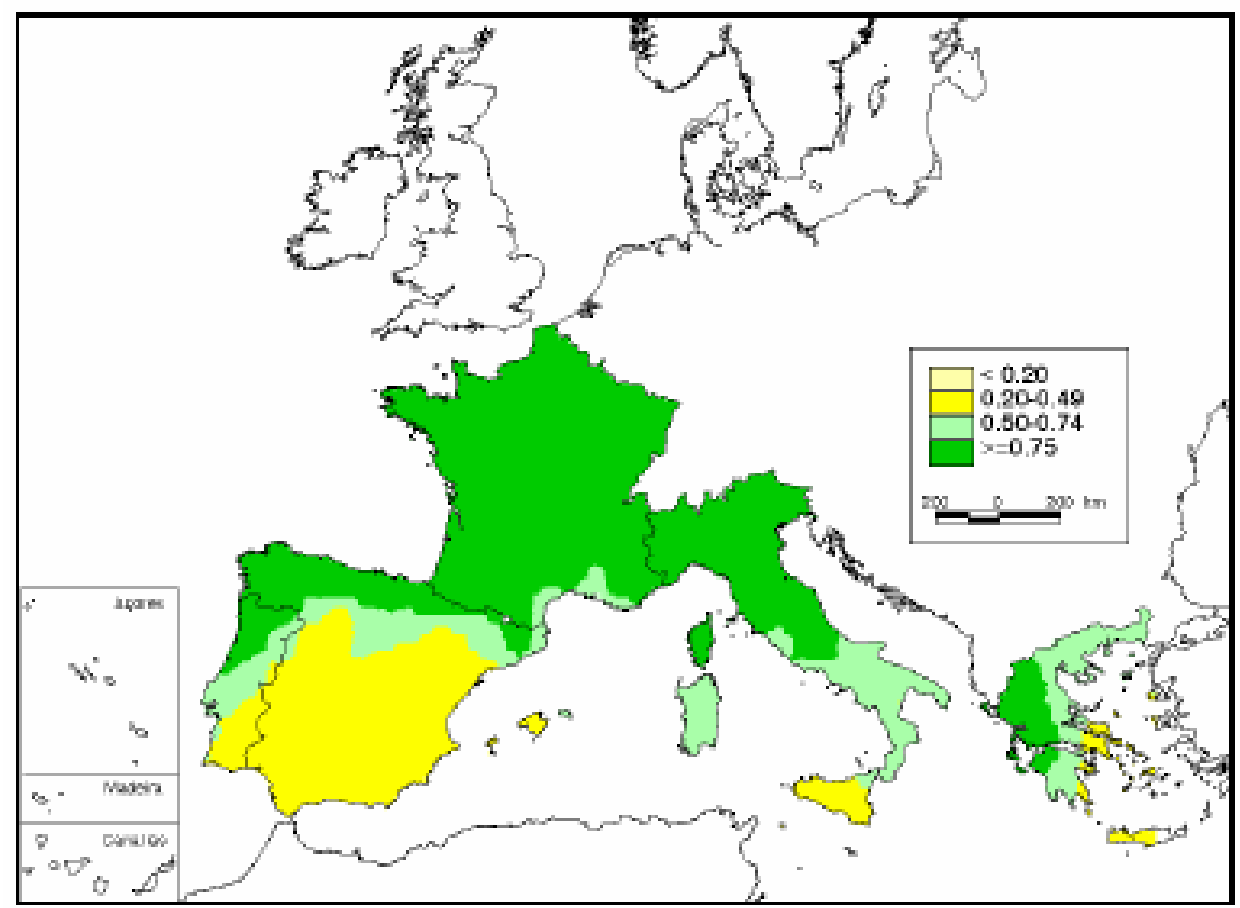

Figure 3. UNESCO' s Indicator of dryness for the Mediterranean Countries in EU

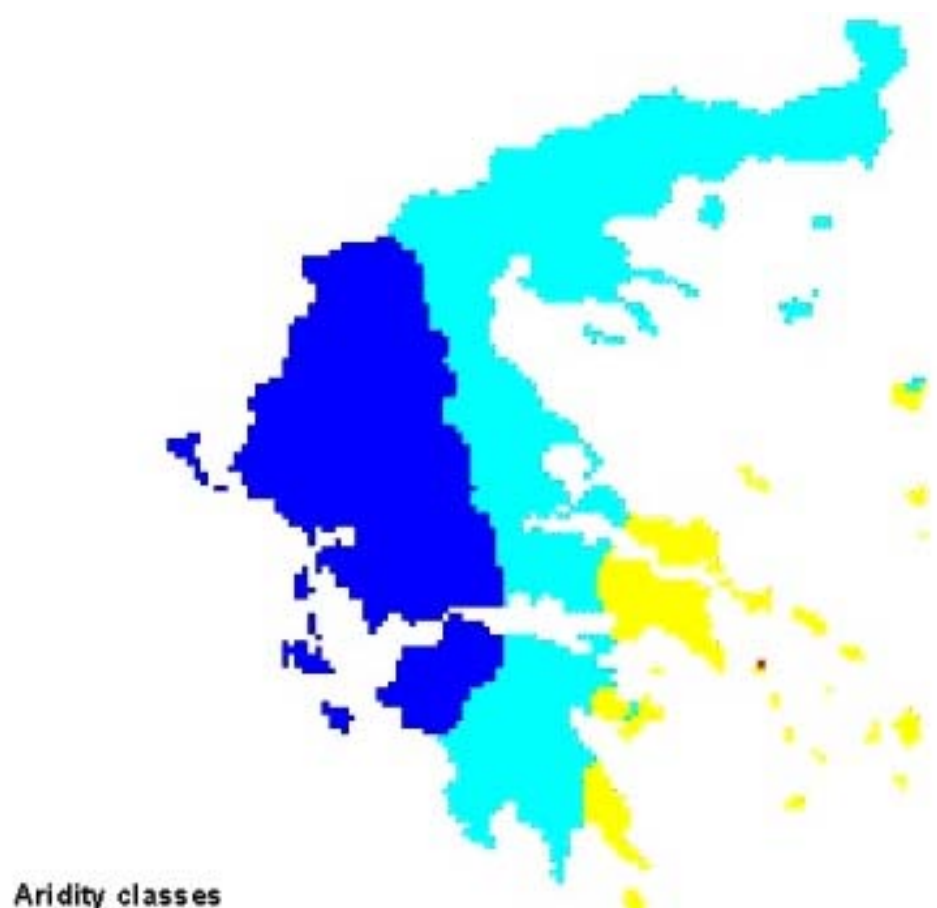

Aridity classes

$<0.20$ (Anid areas)

$0.20-0.50$ (Seni-arid areas)

$0.50-0.75$ (Sub - humid areas)

$\times 0.75$ Humid areas)

Figure 4. Indicator of dryness for GREECE 


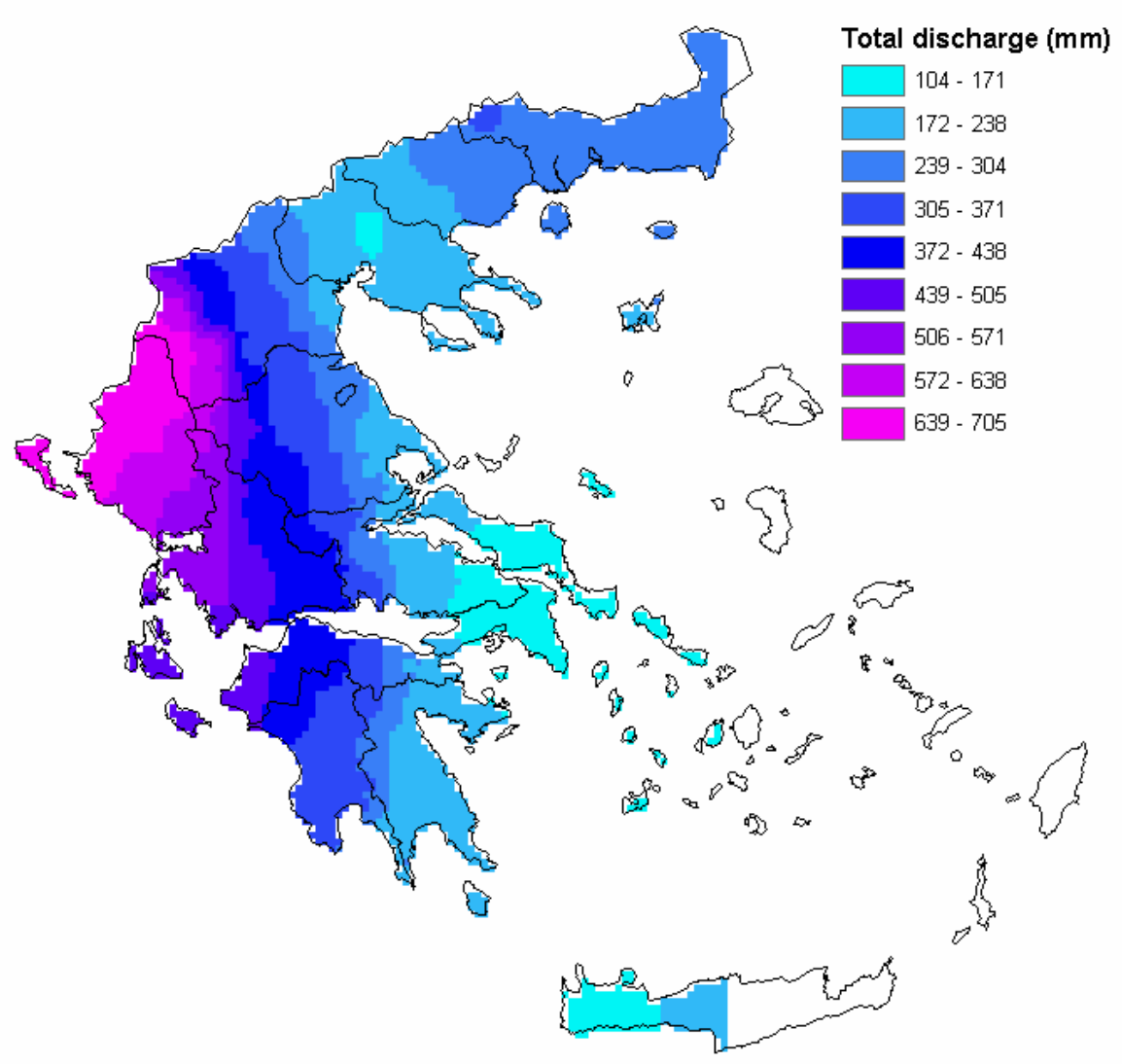

Figure 5. Runoff distribution in Greece

The shortage of water in these regions is also apparent from the distribution of runoff in Greece, which presents an uneven distribution proportional to the rainfall, as shown in Figure 5. All the above provide evidence that water deficiency in the Eastern parts of the country is a permanent situation, one could say "endemic", holding an severity dependent on the weather conditions. Unfortunately, proper action is taken only when these phenomena become extreme and they significantly affect the consumer. However, even these mobilisations are usually based on fire-fighting or repressive measures, while it is obvious that similar situations can only be dealt with a long-term policy of intergrated rational management both of the water resources and the water uses.

\subsection{Water Use}

The shortage of water (drought) in a region is not only related to the availability of the water resources, but also to the water utilization. Unfortunately, as previously mentioned, the major users of water in Greece are mainly located in the Eastern and Southern regions of the country, which is rather disadvantageous as compared to the natural enrichment. Figure 6 presents the percentage sharing of each main category of water uses (urban, rural, industrial and energy) to the available water resources for every Mediterranean country in the European Union [2]. As it results from this figure, but also from Figure 7, Greece does not present a balanced scheme of water uses, as the rural usage takes the lion's share of $86 \%$. More specifically, $96 \%$ of the rural consumption is allocated to irrigation $-80 \%$ of which is wasted in the hydrologic circle or other losses.

The distributions of the urban and rural water utilization for Mediterranean Europe are presented in Figures 8 and 9, while Figure 10 illustrates the distribution of rural use in all the water districts of Greece. 


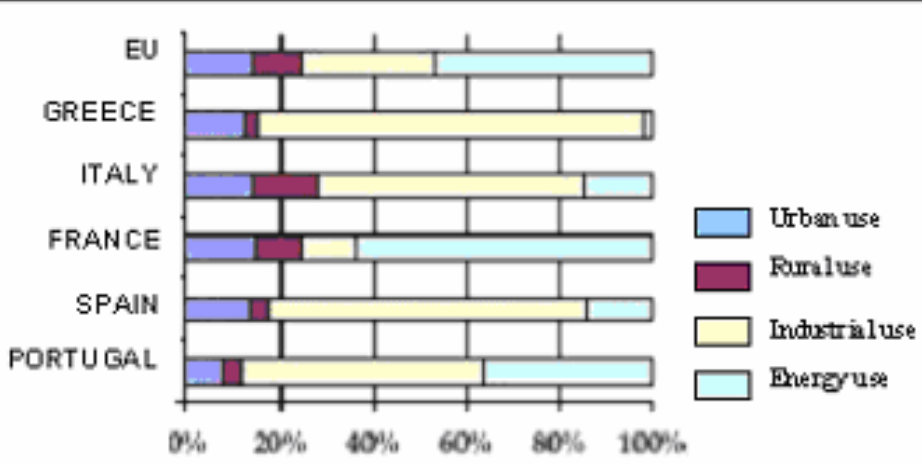

Figure 6. Water Use in the Mediterranean countries and in the EU

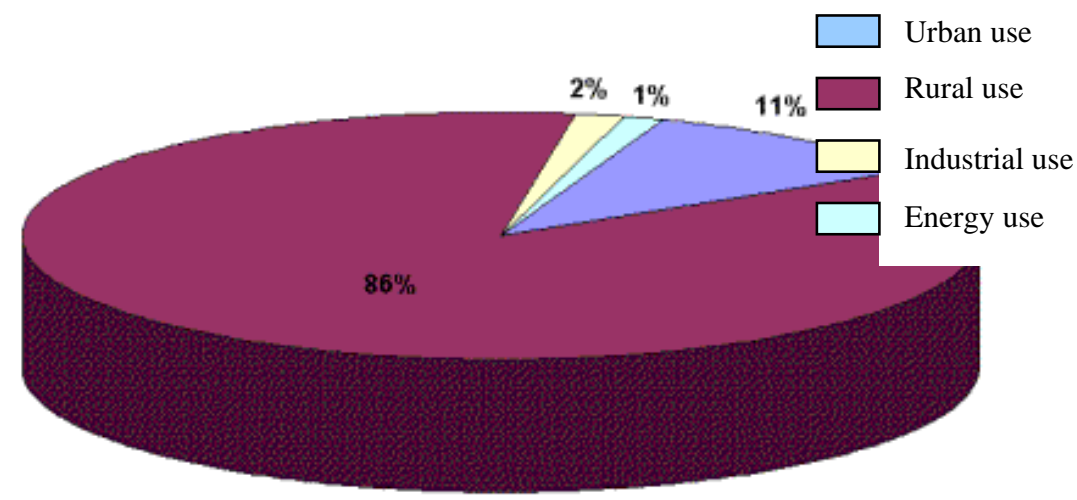

Figure 7. Water Use in Greece

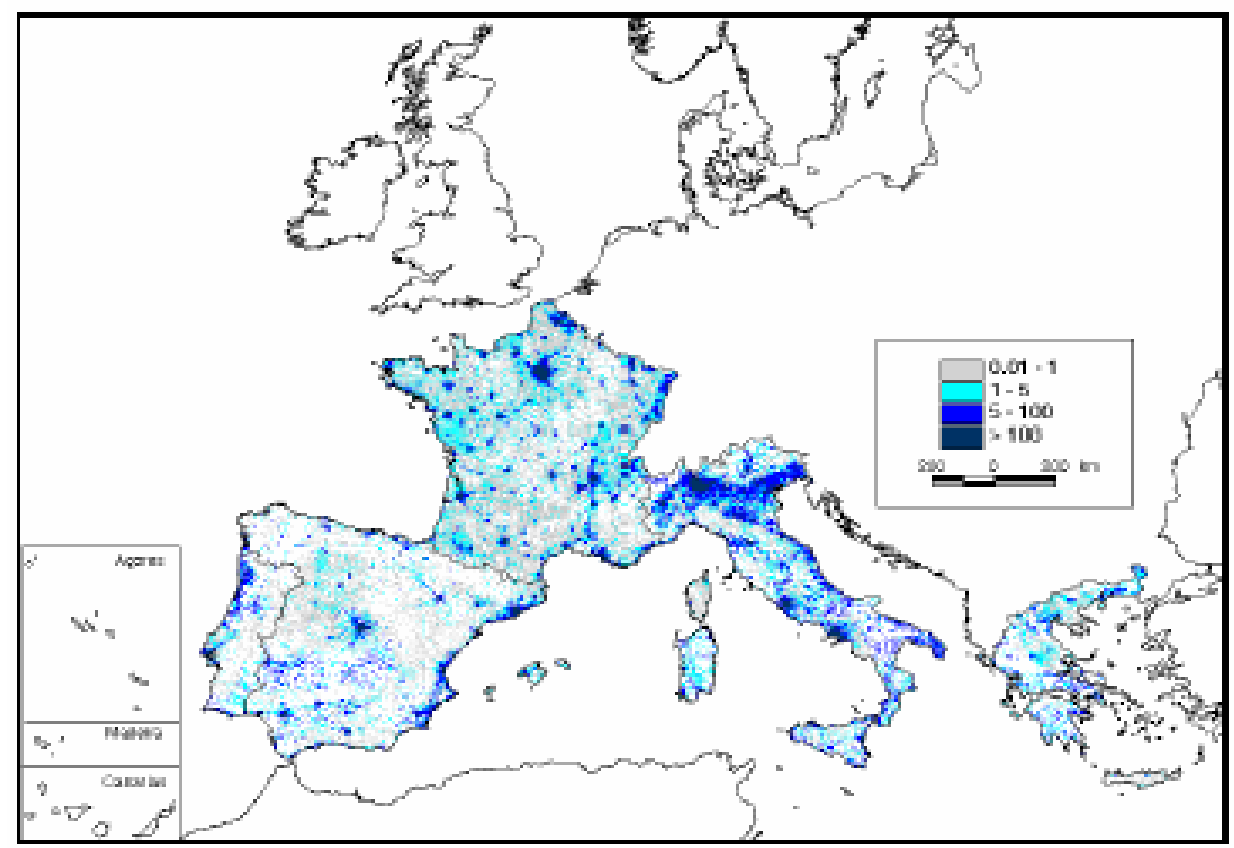

Figure 8. Distribution of urban water demand for Mediterranean countries in EU 


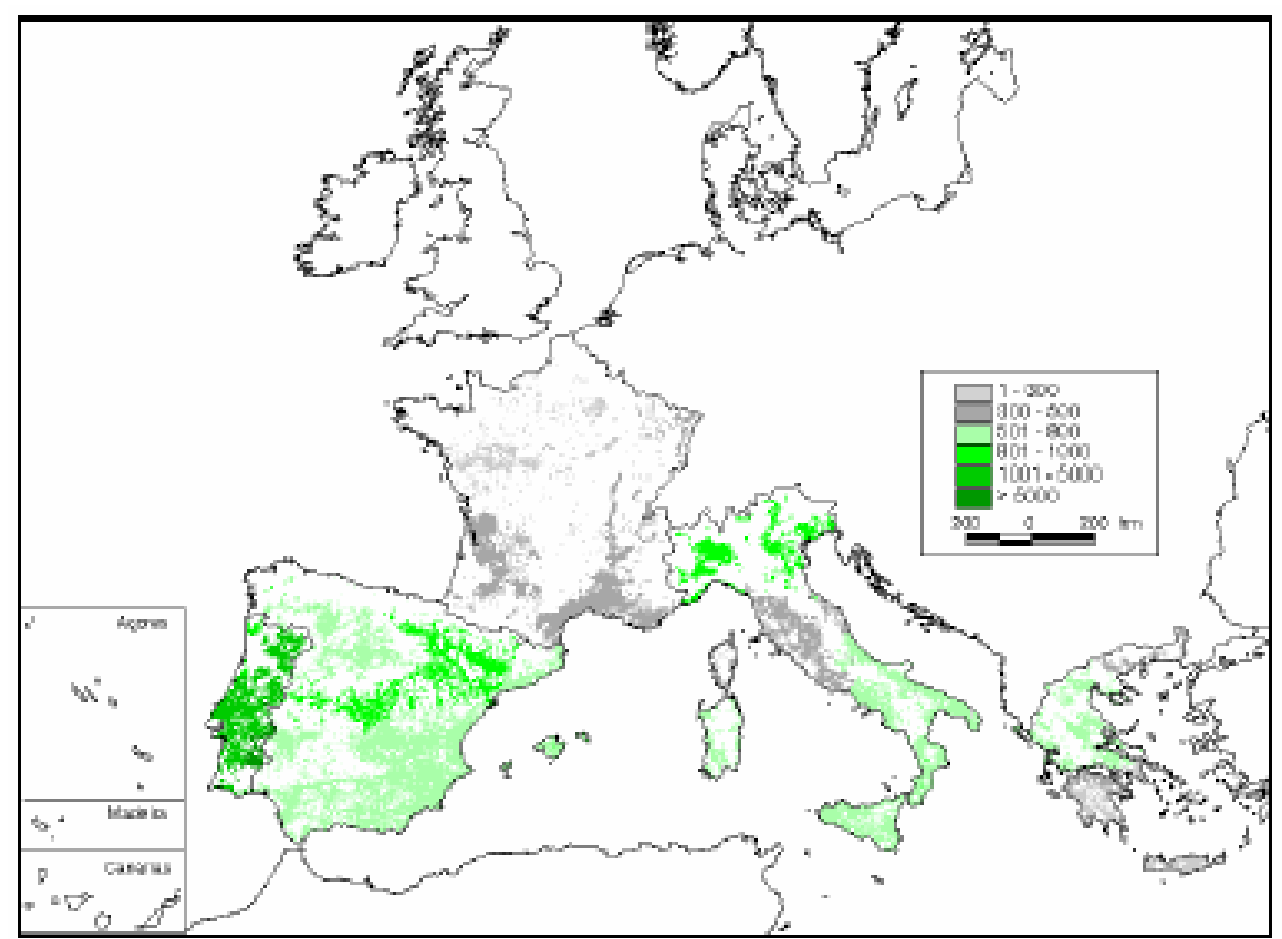

Figure 9. Distribution of rural water demand for Mediterranean countries in EU

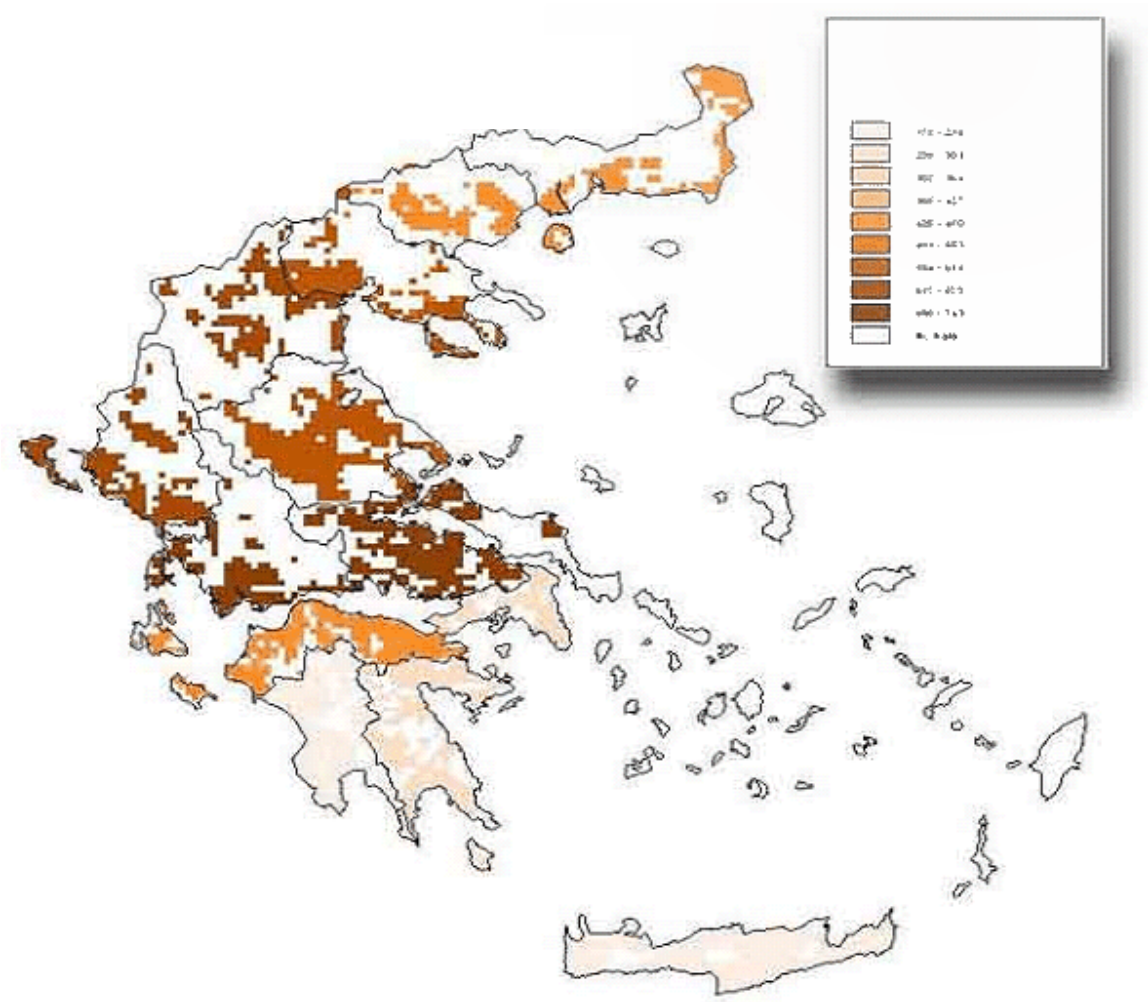

Figure 10. Distribution of rural water demand in Greece

The higher proportion of the urban use is attributed to the water supply. As a result, Figure 8 reveals the intense "centralism" of vast urban areas. Figures 11 and 12 illustrate the urban and rural consumption for all the 14 water districts of Greece. In Greece, the region of Attica leads with a consumption three times greater than that of Central Macedonia, as shown in the bar diagram of Figure 11. 


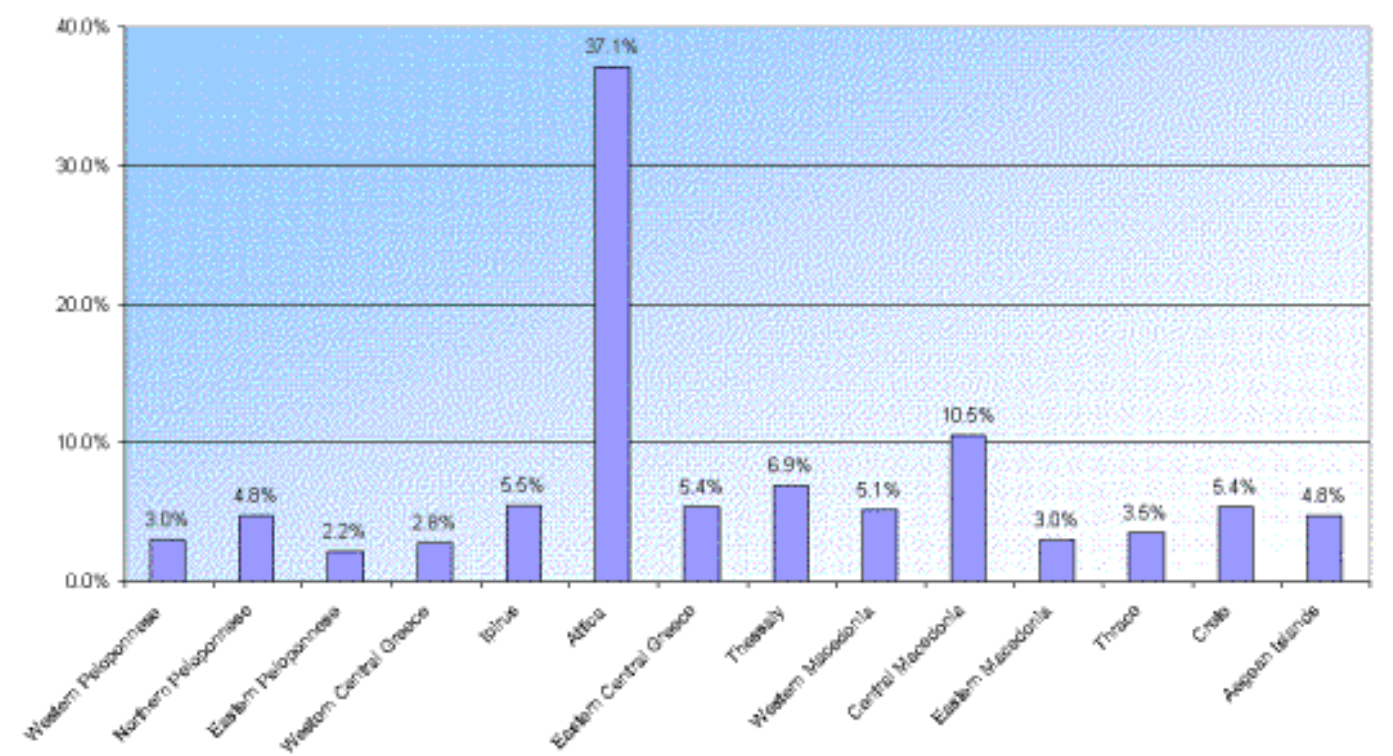

Figure 11. Urban consumption for all the 14 water districts of Greece

For the rural demand, as it appears in Figure 12 and more clearly in Figure 10, the regions of Thessaly, Eastern Sterea Hellas and Central Macedonia take the greater portion. Especially in Thessaly, the rural use is over-doubled than that of Eastern Sterea Hellas, while the hitherto exploitable resources are unable to sufficiently cover the demand.

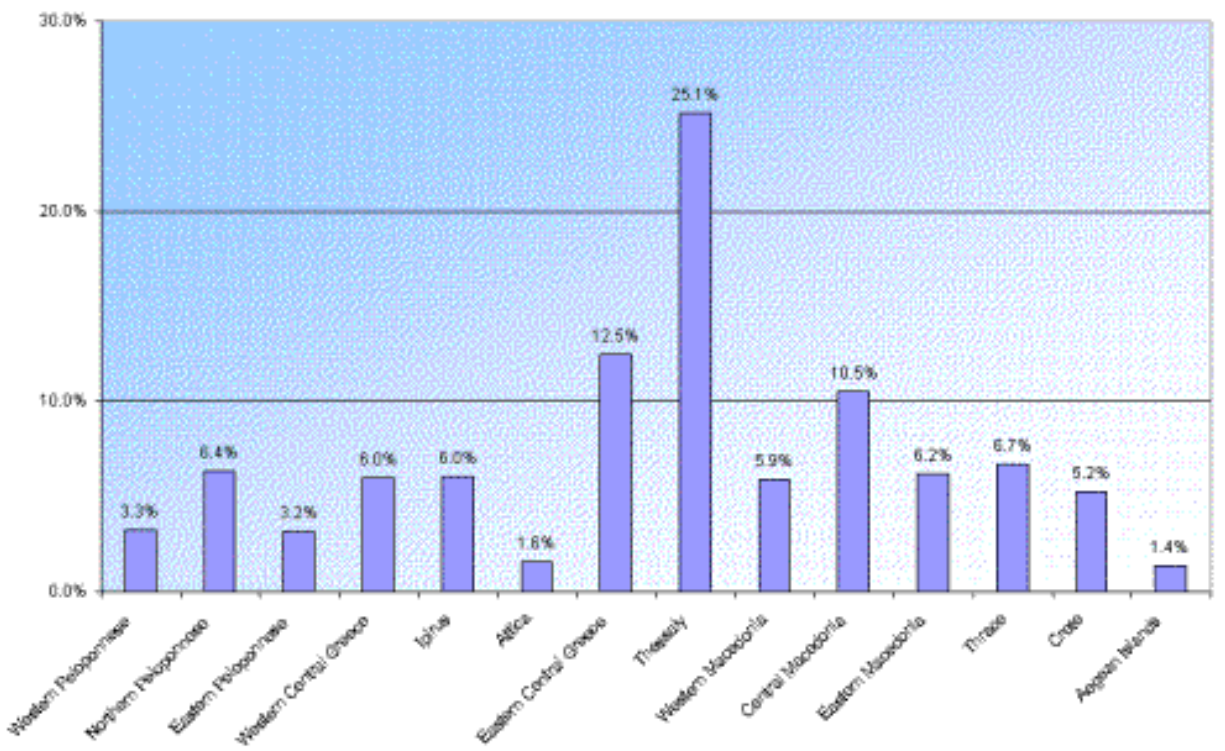

Figure 12. Rural consumption for all the 14 water districts of Greece

This situation will become worse under a systematic climate change due to the greenhouse effect [3]. It is useful at this point to mention that especially for Greece, the study of climatic changes -and their impact to the water resources, the hydraulic works and the water management- is absolutely necessary, due to the danger they imply for the dramatic deterioration of the already problematic water situation [4], [5], [6], [7], [8]. 


\section{CONCLUSIONS AND PROPOSALS}

The hydrologic regime in Greece, as far as the amount of total precipitation is concerned, corresponds to the other Mediterranean countries of the European Union. However, a certain hydrologic particularity considerably differentiates the Eastern regions of the country with the islands of Aegean and Crete, which are particularly problematic regions, as far as their natural enrichment is concerned.

These regions experience an "endemic" shortage of water that appears to be critical. This fact, in combination with the very high water consumption and the water losses in these regions -particularly Thessaly for rural and Attica for urban use- establishes almost permanent conditions of water scarcity, namely permanent insufficiency and shortages of water.

The situation has to be confronted immediately. Moreover, the European Water Framework Directive does not leave margins of time. In every water sector -water resources, hydraulic works, water uses- certain measures should be taken in the direction of equitable estimation, reliable planning, rational management etc. However, even if all these measures (whose detailed report is beyond the aim of this article) could be ideally materialised from the responsible institutions -e.g the Public Power Corporation for the hydropower production, EYDAP for the urban use of Athens, the Ministry of Agriculture for the rural use etc- the results would still be meagre, compared to their implementation cost. Bear in mind that the established polyarchy disallows an integrated approach that would be necessary to plan and implement a national water policy. It is, thus, a necessity to undertake immediate actions towards the direction of a rational reorganisation of the entire water sector in Greece.

Among these actions, the most important are the following:

$>$ Polyarchy in the sector of water should be ceased and, instead, a central institution eg a National Council of Water Resources- should be founded, in order to map out and implement a national water policy. This can be done within the framework of the recently voted by the Greek Parliament Law (3199/2003), where a Special Secretariat within the Ministry of Environment is created, and is called Central Water Service. This institution should be technologically and scientifically supported by a National Water Research Institute, following the existing organisational schemes of other European Countries.

$>$ The Water Framework Directive should be incorporated in the Greek law and be promptly implemented. Our country is quite behind schedule compared to other European countries. The application of the Water Framework Directive should immediately be stimulated in a high scientific and technical level, along with a proportional activation and representation in Europe -in all the sectors offended by the Directive. Failure in this subject will mean a lot more than a libel!

$>$ The water uses should be regarded with a more balanced and rational sharing of the available resources. For the rural use, in particular, a rural national water policy should be immediately planned, at least concerning the proper choice for cultivation of land based on the region's water availability, the observance of the laws regarding exploitation and pollution of underground waters, the vital reduction of water losses and water consumption for irrigations (amendment of irrigation practices etc) and the briefing and guidance of citizens and farmers on these subjects.

\section{REFERENCES}

1. Mimikou, M., (1994), Water Resources Techniques, Vol A \& B, Papasotiriou Editions, Athens (in Greek).

2. CEDEX, (2000), Las aguas continentales en los paises mediterraneos de la Union Europea. Madrid.

3. Mimikou, M., (1993), Climatic Change, In Environmental Hydrology, V.P. Singh (ed.), Kluwer Academic Publishers. 
4. Mimikou, M., Kouvopoulos, Y., Cavvadias, G. and Vayiannos, N., (1991), Regional Hydrological Effects of Climate Change, Journal of Hydrology, 123,119- 146.

5. Mimikou, M., and Baltas, E., (1997), Climate Change Impacts on the Reliability of Hydroelectric Energy Production, Hydrological Sciences Journal, 42 (5), 661 -678.

6. Mimikou, M., Baltas., E., Varanou, E., and Pantazis., K., (2000), Regional Impacts of Climate Change on Water Resources Quantity and Quality Indicators. Journal of Hydrology, 234, 95 - 109.

7. Varanou, E., Baltas, E., and Mimikou, M., (2000), Regional Effects of Climate and Land Use Change on the Water Resources and the Risk Associated with Flooding. Proc. European Conference on Advances in Flood Research, 1-3 November 2000, Potsdam, Germany.

8. Mimikou, M, Baltas, E, Varanou, E, and Fotopoulos, F (2000), Assessment of Climatically Induced Hydrological Changes in Greece. Proc. Int. Conf. on Water Resources and Management, ASCE, July 2000, Minneapolis, Minessota, USA. 